Proceedings of the 50th Hawaii International Conference on System Sciences | 2017

\title{
Exploring Effective Ecosystems in Disaster Management: Case studies of Japan and Nepal
}

\author{
Mihoko Sakurai \\ University of Agder, CIEM \\ mihoko.sakurai@uia.no
}

\author{
Devinder Thapa \\ University of Agder, CIEM \\ devinder.thapa@uia.no
}

\begin{abstract}
Existing literature argues that taking a holistic approach to disaster management is important for organizations in achieving resilience. However, theoretical underpinnings are lacking to achieve a holistic understanding. This paper applies the notion of an ecosystem as a holistic lens to understand complex disaster management.

We report two case studies from Japan and Nepal to illustrate how an ecosystem works during a disaster. The Japan case is a government initiative, whereas the Nepal case is a non-governmental initiative. The theoretical framework of information ecology is used in analyzing the cases.

Based on the findings, we formulate three propositions that show important elements of ecosystems to approach resilience. The study suggests that coevolution is a key to respond to constantly changing situations during a disaster. To accomplish ecosystem coevolution, creating a collaboration system with governments and local communities and embedding local knowledge into the system are essential. Furthermore, digital tools can play a critical role in the coevolution process.
\end{abstract}

\section{An ecosystem as a means to achieve resilience}

In a crisis situation, international and national organizations and individuals from local communities play an important role in providing response and recovery. When we consider effective disaster management, looking at each organization separately is not enough, but having a holistic approach [1] is important [2, 3]. Resilience, which refers to the capabilities of absorbing disturbances [4], is a purpose that disaster relief organizations should achieve in disaster management.

This paper provides a holistic lens to understand how an organization achieves resilience in a disaster situation through collaboration with external organizations. We pay attention to collaboration because collaboration among various players in the field is important during catastrophic events, as it reduces the complexity of the events [5, 6]. To understand its complexity, the social ecology theory [7] and the actor-network theory [8] are applied. However, these theories look into social aspects or network formation process and provide little understanding on the process of adaptation [9].

We apply the notion of an ecosystem $[10,11]$ to guide us to a holistic understanding of disaster management. Resilience theory envisions ecosystems as constantly changing and reorganizing processes [12]. In this sense, during a disaster, we should consider organizations not as stable states [13], but as entities that coevolve to adapt to a particular situation through change and reorganization processes.

This paper presents two different cases from Japan and Nepal to explore an effective ecosystem in disaster management. For this purpose, we use an information ecology framework. We derived the framework from the literature [14], in which the authors define information ecology as "a system of people, practices, values, and technologies in a particular local environment" (Page 49). The concept of information ecology particularly focuses on human activities that are served by technology while the social ecology framework does not have information in its center.

Based on an information ecology perspective, the case analysis shows how key actors collaborate within an ecosystem during a disaster situation, particularly reveals how the actors organize through information sharing among related organizations. In the Japan case, the main focus is on the role of the local government, as it is the agency closest to the residents and has knowledge of the residents and resources in the area [15]. The Nepal case, on the other hand, focuses on the role of digital and local communities in addressing the disaster-related challenges.

The remainder of the paper is organized as follows: (1) a description of information ecology, (2) data collection and analysis, (3) a case description and analysis, (4) discussion, and (5) conclusion. 


\section{Information ecology framework}

Information ecology is considered a complex system of parts and relationships. It exhibits diversity and experiences continual evolution. Different parts of ecology coevolve, changing together according to the relationships in the system. Several keystone species are necessary for the survival of the ecology. In addition, information ecologies have a sense of locality. The key elements of information ecology summarized in Table 1 .

Table 1. Key elements of information ecology [derived from ref. [14]]

\begin{tabular}{|l|l|}
\hline $\begin{array}{l}\text { Key } \\
\text { Slements }\end{array}$ & Description \\
\hline System & $\begin{array}{l}\text { Strong interrelationships and } \\
\text { dependencies developing among } \\
\text { different parts and taking different } \\
\text { forms. }\end{array}$ \\
\hline Diversity & $\begin{array}{l}\text { Different kinds of people, ideas, } \\
\text { technologies and tools that work } \\
\text { together in a complementary way. }\end{array}$ \\
\hline Coevolution & $\begin{array}{l}\text { Capability of adapting to new } \\
\text { constraints and possibilities, which, in } \\
\text { turn, lead to further change. } \\
\text { Information ecologies evolve as new } \\
\text { ideas, tools and activities, and new } \\
\text { forms of expertise rise up within } \\
\text { them. }\end{array}$ \\
\hline $\begin{array}{l}\text { Keystone } \\
\text { species }\end{array}$ & $\begin{array}{l}\text { The presence of keystone species is } \\
\text { crucial to the survival of the ecology } \\
\text { itself, e.g., skilled people whose } \\
\text { presence is necessary to support the } \\
\text { effective use of technology. }\end{array}$ \\
\hline Locality & $\begin{array}{l}\text { Local settings or attributes that give } \\
\text { people the meaning of the ecology. }\end{array}$ \\
\hline
\end{tabular}

\section{1) System}

Like a biological ecology, information ecology is marked by strong interrelationships and dependencies among its different parts. The parts of information ecology may differ from each other.

\section{2) Diversity}

In information ecology, there are different kinds of people and tools. In a well-functioning information ecology, they work together in a complementary way.

\section{3) Coevolution}

A well-functioning ecology is not static, even when it is in equilibrium. Similar dynamics are at work in evolving information ecologies. The pace of new technology development ensures that school, work, and home settings will continue to be offered newer, faster, and different tools and services-not just once, but repeatedly. Information ecologies evolve as new ideas, tools, activities, and forms of expertise arise in them. This means that people must be prepared to participate in the ongoing development of their information ecologies.

\section{4) Keystone Species}

Ecology is marked by the presence of certain keystone species whose presence is crucial to the survival of the ecology itself.

\section{5) Locality}

The habitation of a local context is its location within a network of relationships. To whom does it belong? To what and to whom is it connected? Through what relations? The habitation of a local context is its set of family ties in the local information ecology.

By applying the information ecology framework, we explore how the ecosystem in the cases of Japan and Nepal worked. Though the literature reflects different views of resilience, this paper takes the path of providing capabilities of absorbing disturbances and allows for ongoing, proactive development; i.e., a dynamic, adaptive interplay between sustaining and evolving processes in response to change [16-20]. In this sense, we see how each key element of information ecology framework interacts with the others, informing us of how such a capability is given to relief organizations.

Before moving to the case analyses, we present the approach to data collection in the next section.

\section{Data collection and analysis}

The largest earthquake on record occurred on the east coast of Japan on March 11, 2011. The earthquake, called the Great East Japan Earthquake, was recorded at a magnitude of 9 on the Richter scale and caused massive damage to a very wide area of the country. This earthquake is unique in that it caused a rupture zone $500 \mathrm{~km}$ long and produced a tsunami of 40 meters. The Fire and Disaster Management Agency reported 19,418 deaths, 6,220 injuries, and 2,592 missing as of March 2016. It also reported 121,800 houses entirely lost and more than 1,000,000 partially destroyed. The east coast of Japan has been known as being prone to earthquakes, so local authorities practiced exercises and residents were well prepared; however, the scale of the earthquake was beyond any prior assumptions and caused devastating damage, especially to the northeast coastal area of Japan.

Five months after the earthquake, in August of 2011 , one of the authors conducted a field survey in an inland city called Tono to investigate the damage and situation. Although five months had passed since the 
earthquake, residents of the most damaged places around the coast area were still in a state of panic, so conducting a field survey was impossible. Tono was affected by the earthquake; however, the damage level was less pronounced than in the coastal area. A twohour face-to-face interview has been conducted with the mayor and two officials in the disaster management headquarters. The interview was open-ended but main focus was how they supported neighboring towns where were heavily damaged. The interview was recorded and transcribed. Following the administration of the survey, a presentation given by the same officials at Tono in July 2012, one year after the interview, about their activities of a base for supply and rescue operations to the damaged area was used as supplementary data.

On April 25th, 2015, a 7.8 magnitude earthquake hit Nepal, which caused widespread damage across 14 districts out of 75 in the whole country. On the same day, a powerful aftershock of 6.9 magnitude hit again. More than 8,000 people died, and more than 21,000 people were injured. Four out of the seven UNESCO World Heritage sites in Nepal were severely damaged in the earthquake. Amidst this chaos and panic, Kathmandu Living Lab (KLL) started communicating, enrolling, and mobilizing community people and digital humanitarians all around the world to respond to the earthquake.

One of the authors visited Nepal to conduct a field study in December of 2015. The detailed narratives from the director of the KLL, who had been directly involved in the whole crisis response process, as well as a log book of KLL's skype conversation with different actors were analyzed. In addition to this conversation analysis, we also conducted interviews with locals from Kathmandu (the capital city of Nepal), volunteers from OpenStreetMap (OSM), which is a collaborative project to create a free editable map of the world [21], and the standby task force that was directly involved in the Nepal earthquake event. We also talked to the community members from Timal village near Kathmandu and conducted an in-depth interview with a senior researcher (from a private social science research institute) who is currently doing case studies in Sindhupalchowk (one of the most affected areas). Additionally, we also had an informal discussion with KLL staff members. In total around 20 interviews were conducted. The interview lasts from 30 minutes to 60 minutes. All the interviews were audio recorded and transcribed. We also took detail notes of the interviews and discussions.

Most of the interviews were open-ended and conducted on site. In the interview, we try to acquire a broader understanding of the phenomena, such as who was involved, how different actors responded, how the event change their socioeconomic behavior, what kinds of digital technologies were used and so on. Some additional interviews with the locals of Kathmandu and nearby villages provided a broader contextual picture of the crisis situation in Nepal. The primary data, such as interviews, were supplemented by adding secondary data, such as news articles, government documents on earthquake response, and research articles on KLL.

In analyzing the data, we went through the interview transcripts and extracted the main constructs and mapped those constructs to the five elements of the information ecology framework. The analysis revealed the intricacies of crisis management ecosystem. Throughout the analysis, constant data comparison was conducted to enable holistic understanding of the five elements of information ecology.

\section{Case description and analysis}

In this section, two case studies from the Great East Japan Earthquake in Japan and the 7.8 magnitude earthquake in Nepal are presented. These two cases differ in nature. The Japan case is initiated by the local government in Tono, whereas the Nepal case is initiated by local communities (KLL). So the analysis will highlight how the ecosystem in each case formed and evolved.

\subsection{The case of Tono City in Japan}

One man ran into the disaster response headquarters in Tono on midnight of March 11, 2011. Eleven hours before that, at 14:42 on the same day, the Great East Japan Earthquake hit the east coast of Japan. The man came from a neighboring town called Otsuchi where more than half of the town land had been flooded and washed away by the tsunami. Since roads were destroyed by the earthquake and tsunami, the man climbed up a mountain on his foot and found the headquarters in Tono. He said,

"500 people evacuated to the Otsuchi high school. Water and foods are running out. Please give us a help."

From this moment, Tono became an important base for supply and rescue operations to the heavily damaged coast area. Three hours after the man's arrival, officials of a fire brigade started heading to Otsuchi bringing food, water, fuel, and blankets.

Tono is an inland city located in Iwate prefecture (regional government) where its coast areas were one of the most damaged by the earthquake. The mayor had been thinking that Tono should be a base for supporting the coastal areas at the time of a disaster. Since Tono is $50 \mathrm{~km}$ away from the coastline, the 
mayor views the geographical condition as an advantage.

In 2007, four years before the earthquake, a regional disaster preparedness exercise of providing medical supports and delivering relief was conducted in Tono. The number of participants was 87 organizations from the Iwate region. This exercise resulted in formulating a neighboring municipalities networking association with the purpose of collaborating and supporting each other at the time of a disaster. Nine towns, including Tono, joined this association. At this moment, Tono foresaw that the following functions would be necessary to fulfill its mission as an effective base for relief supply and rescue operations in the time of a disaster:

1) Open the municipal park as a temporary heliport for external organizations providing relief operations in the initial response phase such as the Red Cross or army forces.

2) Using empty land in the town as a parking space and a campground.

3) Transferring serious casualties from damaged areas to inland medical facilities.

4) Providing facilities for storing and managing relief goods (medicine, blankets, water servers, and so on).

5) Providing open space for external organizations to have meetings and for other purposes.

Based on the above assumptions, a disaster exercise with the purpose of supporting damaged areas was conducted again in 2008. More than 18,000 people from 25 neighboring towns, police, a fire brigade, and army forces participated in the one-day event.

The earthquake hit this area three years later. At 15:00 on March 11 in 2011, just 20 minutes after the earthquake, Tono opened a base for external supporting organizations in a municipal park in spite of the fact the earthquake inflicted much damage upon Tono itself to its government buildings. Ten days after the earthquake, the number of people who aggregated in Tono for the purpose of supporting the damaged area was more than 3,500. As of June of 2012, one year and three months after the earthquake, Tono received 6,400 packs of rice $(10 \mathrm{~kg}$ for one pack), 128,000 bottles of water (two liters for each bottle), 178,000 set of clothes and blankets, and 166,000 boxes of food from 44 municipalities all over the country.

Moreover, 13 organizations, including three universities, set up their bases in Tono as support offices.

In addition to providing facilities to external organizations, Tono itself was sending officials to neighboring damaged towns to collect situational information and deliver requested goods. The number of dispatches was more than 300 for the first six months after the earthquake. Dispatched officials delivered relief goods and returned back to Tono with requests from the damaged area. Since information and communication technology (ICT) was damaged, officials were the only way to collect and deliver information. They simply repeated information collection and relief goods delivery. The disaster exercises in 2007 and 2008 helped smooth actions in the initial response phase; however, the exercise did not assume the delivery of relief operations for such a long time. It was beyond the scope of the exercise. Decisions were made by the mayor based on the constantly changing situation with constant improvisations. Other local governments offered their experience and knowledge to Tono on how to deal with the situation. It helped Tono a great deal.

The failure of ICT, especially in terms of a blackout, is what Tono city did not predict when conducting the exercises. Until the power supply resumed two days after the earthquake, a radio broadcasting accessible by a radio-charged battery was the only way to grasp the situation. If the man from Otsuchi town had not come into the disaster headquarters office, Tono would not have known how devastating the situation was in Otsuchi. Officials sent to the damaged areas were the means to having knowledge of the situation; however, it took some time to go back and forth so the information was not always current. Since the situation in the area was changing all the time, getting real-time information was critical for mobilizing relief operations. The mayor of Tono recalled the situation and said the following:

"For several weeks after the earthquake, every supportive organization was in a state of panic, and information received from them was sometimes incorrect. Reports from officials we sent to the damaged area were the most reliable information sources. However, I believe that since army forces or police should have known the situation in the towns in the coastal area better than us, we would have been able to mobilize relief operations more quickly if we had been given the situational information on heavily damaged area."

Since all organizations, i.e., Tono as a local government, Iwate as a regional government and police, a fire brigade and army forces as external organizations, were conducting relief operations separately, information was not shared among them. Tono was forced to collect related information on their own. In the heavily damaged area, sending requests outside town was impossible because damaged municipalities lost all communication channels, including the power supply. Only human beings could deliver information and ask for help. 


\subsection{Analysis of the Japan case}

We organize our findings around key elements of information ecology, which are shown in Table 1. The focus is to understand how the ecosystem worked in Tono during the earthquake and what the challenges were.

\subsubsection{System}

"System" aims at building interrelationships among different parts of information ecology. The mayor of Tono has been aware of the importance of organizing a collaborative platform in case the coastal area is destroyed by the disaster. The regional disaster exercise was conducted in 2007 with 87 organizations from the area. One year later, the extended exercise took place in the same manner, with neighboring towns, police, a fire brigade, and army forces.

Emergency management has been categorized into four components: mitigation, preparedness, response, and recovery [22-24]. The exercise mainly focused on preparedness and response phases. The scope of responses in this exercise was not long-term, but rather short-tem, namely the initial response [25] phase. In reality, during the earthquake, disaster management operations lasted for more than one year, and this was beyond prior assumptions.

\subsubsection{Diversity}

The literature points out nurturing "diversity" is one of the critical factors in building resilience in social ecological systems [12]. Different kinds of organizations participated in the regional disaster exercises. Through the exercises, they shared procedures on how to react to a disaster in the initial response phase; however, tools or information systems were developed separately for each organization. In addition, note that the exercise succeeded in creating a collaborative platform among public organizations, but failed to involve local residents or communities, and voluntary associations.

\subsubsection{Coevolution}

"Coevolution" involves generating new ideas, tools, or activities. The first regional exercise resulted in formulating a networking organization of nine neighboring towns in Tono. In this sense, the networking association is one form of coevolution. The learning process is a key mechanism for the evolution in social ecological systems [26]. As the case shows, since the earthquake was quite large and beyond prior assumptions, disaster management operations were prolonged for several months and years. The exercise focused on the short-term response, and Tono did not possess knowledge on how to deal with the prolonged situation. Another regional government in Shizuoka prefecture located $700 \mathrm{~km}$ away from Tono provided knowhow on how to deal with the situation, as it was not affected by the earthquake. Shizuoka prefecture has gained knowledge through its experience since the Shizuoka region covers the central east coast of Japan and is prone to earthquakes. The officials in Tono recalled the situation and said the following:

"The knowledge provided by Shizuoka enabled us to develop our own procedure for acting as a relief supply and rescue base operator for such a long time."

\subsubsection{Keystone species}

In this case, Tono plays a critical role in configuring an ecosystem with "keystone species." The basic functions that Tono provided to external relief organizations were opening their land for multiple purposes, such as a heliport, a transportation hub for injured persons, medicine and other relief goods, and meetings. In addition, lodges were offered by local communities. At the end of March, 2011, the social welfare councils of Tono organized networks of individuals and voluntary associations. They prepared to receive volunteers from all over the country and matched needs from the damaged area and skills of volunteers. The social welfare councils and citizen volunteers made more than 140 thousand rice balls that were delivered to the affected towns. Tono is important not only in its geographical conditions, but also in its capability to aggregate related individuals and associations together, although these associations were not included in the exercise.

\subsubsection{Locality}

Communication tools such as landline, mobile phones, and the Internet were useless because the power supply was cut down. The only means to collect "local" information was city officials. However, in this case, the local context had not been shared among related organizations, even if the power supply would have continued. Since the long-term disaster operations were out of the exercise scope, the common tools for supporting information sharing were not developed in advance. Each organization collected information separately. Difficulty in information sharing was the biggest challenge for Tono in providing supply and rescue base services. The exercise succeed in cultivating initial response procedures as domain knowledge [27], while it did not cover a longer response phase, which requires local contexts to keep track of what happened and what was needed.

\subsection{The case of KLL}

$\mathrm{KLL}^{1}$ is an active and growing technology community established in 2013 to improve urban planning and management. The community is comprised of software start-ups, tech incubators,

\footnotetext{
${ }^{1}$ http://www.kathmandulivinglabs.org/
} 
universities, and the local OSM chapter including mapping volunteers from all around the world. With the motto of "together we can do more," KLL harnesses local knowledge, develops open data, and promotes civic technologies.

On April $25^{\text {th }}, 2015$, a 7.8 magnitude earthquake hit Nepal, which caused widespread damage across 14 districts. Amidst this chaos and panic, KLL people started brainstorming how to respond to the earthquake. The next day, KLL established a room for the headquarters for its earthquake response in a parking area because the office was damaged. The headquarters office explained KLL's actions in the relief effort and how others could help. The director of KLL was aware that this work could not be done alone and locally; therefore, he contacted the Digital Humanitarian team that evening. The Digital Humanitarian team is a volunteer network, including the standby task force [21], to seek help from the international OSM community. This network is unique in using digital tools to respond to a crisis situation.

KLL received an unprecedented response from volunteer mappers. Within 48 hours after the earthquake, over 1,500 people begin to remotely map the affected area in OSM using aerial imagery. To speed up their response program, they deployed QuakeMap volunteers. The purpose was to bridge the information gap between the quake victims and relief agencies.

KLL coordinated with and engaged mappers throughout the world using online chat platforms, such as Skype. Meanwhile, the demand for maps and data was growing. Individuals, volunteer groups, and humanitarian organizations began to request data and printable maps for relief operations from KLL. Around 2,200 volunteers have contributed through remote mapping. In the course of extending their services, KLL established contact with the GIS division of the Nepal army. KLL received requests to map camps of Internally Displaced Persons (IDPs) who are displaced due to the earthquake. To handle this problem, KLL asked volunteer mappers to assist in locating IDP camps with aerial imagery. KLL also provided a training session to doctors who were involved in the relief operations. KLL members trained the doctors in how to use OSM and QuakeMap to determine where their help was needed. At this point, 3,300 mappers have assisted in mapping in OSM. To meet the need for digital data and printable maps of the affected districts, KLL introduced QuakeRelief, a repository of printable maps that used the data mapping that volunteers have added to OSM Nepal.

Within a month of operation, The New York Times reported on KLL's earthquake response efforts. The news further helped in spreading the word about what
KLL was doing. This was the first time KLL's work appeared in major international news media after the earthquake. The international news pulled the attention of the Nepal government, which consequently recognized KLL's work.

On May $1^{\text {st }}$, 2015, the National Information Technology Center (NITC), which facilitates ICTenabled delivery of all government services in Nepal, listed QuakeMap on its website as an important part of the local earthquake response initiative. KLL also began working with UNESCO and the Department of Archeology to document the condition of cultural heritage sites in the Kathmandu Valley. KLL developed a mobile data collection app and held a training course to show volunteers how to report the conditions of sites in the mobile app.

On May 12, 2015, an aftershock of 7.3 magnitude further damaged the affected districts, serving as a strong reminder of the importance of both recovering from disasters and preparing for future natural disasters. The aftershock made KLL's office too dangerous to enter; therefore, the office moved to another temporary location in a building at Kasthamandap School. At this point, QuakeMap continued to be a vital tool in the earthquake response with 1,500 reports about the needs from victims and relief efforts. Volunteers analyzed and classified the reports and followed up the reports until they were resolved. In the aftermath, on May 18, a landslide blocked a river called Kali Gandaki, highlighting a need for continued mapping. The blockage created a temporary dam, which led to massive flooding upstream of the dam.

On May 24, KLL moved to a new. On July 7, the Department of Education, Central Bureau of Statistics (CBS), and The World Bank collaborated with KLL to support an assessment of damage to schools in affected zones. KLL's expertise in mobile data collection technology made the collaboration possible. Similarly, KLL and international academic institutions jointly held a workshop to discuss the role of data and technology in the relief efforts following the earthquake in April. Along with Kathmandu University and UAViators (unmanned aerial vehicle), KLL coorganized a workshop on using Unmanned Aerial Vehicles (UAVs), or drones, for humanitarian work. The high-quality aerial imagery that UAVs collect can be used for assessing damage and planning reconstruction. After its successful completion of the response program, KLL closed QuakeMap.org. They currently moved their focus to the recovery phase. KLL is involved in the work of school infrastructure damage assessment. The updated OSM data-created by the work of 9,000 volunteers from around the world- - continues to serve as an important resource. 
KLL is working continually in enrolling new actors and mobilizing the actors into other crisis management activities, such as housing damage assessment. The assessment uses mobile data collection to assess housing damage through all earthquake-affected districts.

\subsection{Analysis of the KLL case}

Based on the five key elements of information ecology, we have identified various entities of KLL Nepal, their interaction with various players, and their coevolution. These are elaborated upon below as follows.

\subsubsection{System}

In the KLL case, a structured system, such as the regional exercise flame, does not exist; however, as introduced in the previous section, KLL consists of several organizations. KLL is not just one organization or individual, but rather a network hub of digital humanitarians (standby taskforce), OSM mappers, local communities, doctors, national and international (remote) volunteers, the Nepal army, and government organizations. KLL was founded by a social entrepreneur with the purpose of implementing mobile and internet-based technology solutions for open government and civic innovation to enhance urban resilience and civic engagement. KLL has since grown into an active technology community established to improve urban planning and management. They now deal with identifying the usage of technologies in solving complex problems, such as response and recovery in emergency circumstances. As we can see, interdependencies among various players have been embedded in the system of KLL from its origin.

\subsubsection{Diversity}

In the KLL case, each player had a clear role. The role of the digital humanitarian team was to map and cluster the data, the Nepal army was focusing on sending the personnel to affected areas, aid agencies wanted to send their resources, and doctors were volunteering to provide medical facilities. The local communities were also working collectively to find out about the victims, and the role of KLL was to coordinate between all these actors and analyze the huge amount of data. In contrast to the Japan case, the KLL network did not include governmental organization in their first attempts.

\subsubsection{Coevolution}

Information ecology is not static. It is constantly evolving [14]. Similar dynamics can be seen in the case of KLL. Digital tools, such as chat rooms, mapping tools, email systems, UAVs, GPS systems, and social media, served as mediators in carrying out the rescue operations. In fact, without these technologies, it was quite difficult to get the real-time location of the victims and to conduct the measurement of the hazards.

These development efforts resulted in collaborative works with KLL and the international/governmental organization such as the Department of Education in Nepal, CBS, and the World Bank to create new services (damage assessment works) in the affected areas.

\subsubsection{Keystone species}

In the KLL case, KLL, digital humanitarians such as the standby taskforce, OSM, Nepal Army, and aid agencies, including government organizations, were essential. However, KLL in this context as a keystone species coordinates organizational collaboration as well as thousands of international mappers.

\subsubsection{Locality}

Locality is a particularly important attribute of information ecologies. Only people who are immersed in a particular information ecology can provide a local habitation and a name for new technologies [14]. For instance, in this case the main actor was KLL, which has a greater understanding of the local context and their socio-geographical configuration, and thus, the local communities and local governments, which have a better understanding of local needs, and legitimacy compare to outside interventionist. KLL developed OSM, QuakeMap, and other digital tools, which helped KLL to gather the local context into the map.

\section{Discussion}

The notion of resilience enhances the capacity of social ecological systems to adapt to uncertainty and surprise [28]. The purpose of this paper is to explore the way to achieve resilience from an ecosystem perspective. Two cases from Japan and Nepal are analyzed based on the information ecology framework. The findings are summarized in Table 2.

Table 2. Key elements of information ecology in Japan and Nepal

\begin{tabular}{|l|l|l|}
\hline System & Tono (Japan) & KLL (Nepal) \\
\hline disaster exercises & $\begin{array}{l}\text { KLL (software } \\
\text { start-ups, tech } \\
\text { incubators, } \\
\text { universities, local } \\
\text { OSM chapter) }\end{array}$ \\
\hline
\end{tabular}




\begin{tabular}{|c|c|c|}
\hline Diversity & $\begin{array}{l}\text { Tono city, } \\
\text { neighboring } \\
\text { towns, police, a } \\
\text { fire brigade, army } \\
\text { forces, local } \\
\text { communities, } \\
\text { volunteers }\end{array}$ & $\begin{array}{l}\text { Digital } \\
\text { humanitarian } \\
\text { team, Nepal army, } \\
\text { doctors, local } \\
\text { communities }\end{array}$ \\
\hline Coevolution & $\begin{array}{l}\text { A networking } \\
\text { association of } \\
\text { neighboring } \\
\text { towns, knowledge } \\
\text { share from } \\
\text { Shizuoka } \\
\text { prefecture }\end{array}$ & $\begin{array}{l}\text { OSM, QuakeMap, } \\
\text { chat rooms } \\
\text { Collaboration } \\
\text { with the } \\
\text { Department of } \\
\text { Education, CBS, } \\
\text { and the World } \\
\text { Bank }\end{array}$ \\
\hline $\begin{array}{l}\text { Keystone } \\
\text { species }\end{array}$ & $\begin{array}{l}\text { Tono city, the } \\
\text { social welfare } \\
\text { councils }\end{array}$ & KLL \\
\hline Locality & $\begin{array}{l}\text { Tono city } \\
\text { officials }\end{array}$ & $\begin{array}{l}\text { KLL, local } \\
\text { communities, } \\
\text { local governments }\end{array}$ \\
\hline
\end{tabular}

The Japan case has effectively been operationalized by the government organizations, whereas participation from local communities as well as digital communities was not strongly embedded in the ecosystem. This results in lack of information sharing and prevents effective disaster management.

In the Nepal case, the use of digital tools and the involvement of digital communities, such as digital humanitarians and mapping communities, were visible while the collaboration for information sharing between government organizations was lacking. For example, in the beginning, the government organizations and aid agencies were skeptical about using KLL's mapping information. They attempted to use their own authentic channel. This might have hindered the KLL's crisis response team; however, the recognition of real-time mapping through crowdsourcing by various national and international media and digital humanitarian communities helped KLL to convince government and aid agencies. Consequently, these agencies also enrolled in the KLL crisis response team. Although there has been collaboration regarding the use of digital mapping, less efforts have been made by the government to apply the channels in practice. Hence, the distribution of relief goods was not effective.

Based on the findings, we introduce three propositions for an effectively functioning ecosystem in disaster management.

Proposition 1: A government initiative is essential to formulate a structured system with diverse players.
The regional disaster exercises in Tono provided a geographical foundation of collaboration during the Great East Japan Earthquake. Tono was a hub to pass relief goods offered by 44 municipalities around Japan to the damaged area. However, the exercise was only open to government organizations, such as army forces, a fire brigade, police, and so on. After the earthquake, local communities, such as voluntary associations, were organized with the initiative taken by the Tono social welfare councils. Local communities including volunteers were organized flexibility in a selforganized [29, 30] manner under the initiative of Tono.

Looking at the case of KLL, they formed structured relationships among different players in the local community, except the government organizations. As a result, KLL succeeded in collecting situational information on OSM and other digital tools. However, they did not have the capability to mobilize relief goods distribution, while government organizations have this. It took some time until KLL was acknowledged by them as a reliable aid agency to cooperate. When governmental organizations join the platform, they require social trust to judge the reliability of the platform. KLL acknowledged social trust, mainly as reported by national/international media.

In summary, the literature pointed out the importance of diversity of a social ecological system [12], however, the information ecology framework does not suggest how diverse actors collaborate to formulate a structured system. In our analysis, we find the importance of the government initiative especially in a crisis management situation that managing relief goods operations become critical. Forms of such a structured system vary, i.e., exercises, a collaborating network, and so on. Efforts to involve local communities should be made in the preparedness phase to mobilize an effective ecosystem in the time of the event.

Proposition 2: Gathering local knowledge is essential for promoting the coevolution of the ecosystem.

In the information ecology framework, the importance of five elements was not characterized. Through our case analysis, we find that coevolution is the most important element for a functioning ecosystem in disaster management, as disaster management is unique in responding to constantly changing situations. Damages and demands differ place by place, which makes disaster management complicated and unpredictable. An ecosystem should learn and evolve through the entire response phase.

Coevolution embeds leaning features in its process [26]. Shizuoka provided knowledge to Tono on how to 
react to the prolonged disaster situation, which helped Tono to adapt to an unexpected situation. A networking organization of nine neighboring municipalities generated an opportunity to obtain relief goods from 44 municipalities. Local knowledge enabled Tono to learn and applied a new form of relief supply and rescue operations.

More than several thousand volunteers helped to collect local knowledge in Nepal. KLL's actions were visible through chat rooms, allowing volunteers to understand what they were doing and going to do. QuakeMap, developed by KLL through crowdsourcing, especially involving digital humanitarian and local communities, solved the information gap Tono was facing, that is, the gap between the needs of affected areas and relief organizations. Tono succeeded in formalizing a public organization's network as well as involving local communities subsequently; however, they failed to acquire the proper information from the field. As a result, the ecosystem stopped coevolving. On the other hand, KLL's various attempts to gather local knowledge and connect those to actual relief activities enhanced further collaboration with the Department of Education, CBS, and the World Bank. All the actors started to believe in KLL mapping and make it standard locating tools rather than paper-based traditional maps; then, they started moving toward using digital tools for mapping crisis situations.

In summary, coevolution is necessary to respond to constantly changing disaster situations. Coevolution in both cases can be observed as the result of sharing local knowledge. In this sense, locality can generate domain knowledge. The degree to which local knowledge is gathered affects ecosystem performance and further disaster management operations.

Proposition 3: Execution of digital tools by keystone species can enhance local knowledge sharing and enable effective relief operations.

As a result of understanding importance of local knowledge share, a question that arises is: How should local knowledge be shared? Since no digital tools were embedded in the ecosystem in Tono, city officials were the only means to collect local information. Tono's initiative enabled diverse players to gather, but tools for information collection were developed separately. This forced Tono to take much more time to obtain real-time information than usual, while QuakeMap received more than 1,500 reports from victims and relief efforts within 48 hours after the earthquake. The KLL case is unique in that the development of digital tools emerged corresponding to the situation. They did not prepare any tools in advance; however, starting with OSM, QuakeMap bridged disaster victims' demand and relief agencies. Around 9,000 volunteers from all over the world contributed to creating OSM remotely. Following these tools, QuakeRelief as a repository of printable maps and several mobile data collection apps for reporting field conditions were chronologically developed. The literature points out the importance of improvisation in response [31] and intuitive procedures for disasters $[5,6]$. This is a future topic that can be studied to explore why KLL succeed in improvising their response by developing several new communication tools during the earthquake.

In summary, it is apparent that execution of these digital tools by keystone species can enhanced local knowledge gathering; however, at the same time we recognize that integration of the tools are necessary and it is impossible to prepare all the appropriate tools before an event. Tools should be developed corresponding to a situation that is changing all the time. What local governments can do is maintain their connection to communities that are capable of developing such digital tools.

\section{Conclusion}

This paper reports two cases from Japan and Nepal to establish a holistic approach to disaster management. A theoretical lens of an ecosystem and the information ecology framework are applied to the case analyses. Three propositions that guide us in further understanding how an ecosystem works are presented.

From an ecological perspective, the mutual dependency between diverse players and the coevolution process should function in a proper way. By looking at the interrelationships of each element in information ecology, we can gain insight into how an ecosystem works [32].

The propositions show the importance of governmental initiatives to involve several players and maintain an ecosystem's diversity. Even if engagement is accomplished in a self-organized way, the government plays an important role in delivering relief operations (especially the distribution of relief goods). Coevolution is the key element in a functioning ecosystem, but we should take into account the local context [33]. In this sense, gathering local knowledge is essential for promoting coevolution. Digital tools support local knowledge sharing, but they are developed in the field.

While the results are only from two cases, at the same time, we believe these findings can contribute to the research by providing the means for how an organization achieves resilience. In addition, the propositions suggest how to make disaster management systems sustainable and effective. We 
believe these findings can be applied in solving real problems in practice.

[1] B.W. Ritchie, Chaos, crises and disasters: a strategic approach to crisis management in the tourism industry, Tourism Management, 25(6) 2004, pp. 669-683.

[2] H. Baharmand, K. Boersma, K. Meesters, F. Mulder, J. Wolbers, A multidisciplinary perspective on supporting community disaster resilience in Nepal, in: Information Systems for Crisis Response and Management, Rio de Janeiro, Brazil, 2016.

[3] R. Soden, N. Budhathoki, L. Palen, Resilience-Building and the Crisis Informatics Agenda: Lessons Learned from Open Cities Kathmandu, in: Information Systems for Crisis Response and Management, Pennsylvania, USA, 2014.

[4] C.S. Holling, Resilience and Stability of Ecological Systems, Annual Review of Ecology and Systematics, 4(1) 1973, pp. 1-23.

[5] C. Perrow, The Organizational Context of Human Factors Engineering, Administrative Science Quarterly, 28(4) 1983, pp. 521-541.

[6] C. Perrow, Normal accidents: Living with high-risk technologies, Basic Books, NY, 1984.

[7] W.G. Astley, C.J. Fombrun, Collective Strategy: Social Ecology of Organizational Environments, The Academy of Management Review, 8(4) 1983, pp. 576-587.

[8] J. Sabou, S. Videlov, An analysis on the role of trust in digital humanitarian actor networks, in: Information Systems for Crisis Response and Management, Rio de Janeiro, Brazil, 2016.

[9] D.J. Wood, B. Gray, Toward a Comprehensive Theory of Collaboration, The Journal of Applied Behavioral Science, 27(2) 1991, pp. 139-162.

[10] J.F. Moore, The Death of Competition: Leadership \& Strategy in the Age of Business Ecosystems, Harper Collins, NY, USA, 1996.

[11] M.E. Porter, M.R. Kramer, CREATING SHARED VALUE, Harvard Business Review, 89(1/2) 2011, pp. 6277.

[12] F. Berkes, Understanding uncertainty and reducing vulnerability: Lessons from resilience thinking, Natural Hazards, 41(2) 2007, pp. 283-295.

[13] C.S. Holling, From Complex Regions to Complex Worlds, Ecology and Society, 9(1) 2004.

[14] B.A. Nardi, V. O'Day, Information Ecologies Using Technology with Heart, MIT Press, Cambridge, MA, USA, 1999.

[15] M. Sakurai, R.T. Watson, C. Abraham, J. Kokuryo, Sustaining life during the early stages of disaster relief with a frugal information system: learning from the great east Japan earthquake, Communications Magazine, IEEE, 52(1) 2014, pp. 176-185.

[16] J.M. Anderies, M.A. Janssen, E. Ostrom, A framework to analyze the robustness of social-ecological systems from an institutional perspective, Ecology and Society, 9(1) 2004, pp. [online] URL: http://www.ecologyandsociety.org/vol9/iss1/art18/.

[17] F. Berkes, J. Colding, C. Folke, Navigating socialecological systems : building resilience for complexity and change, Cambridge University Press, Cambridge, 2003.

\section{References}

[18] L.H. Gunderson, Managing surprising ecosystems in southern Florida, Ecological Economics, 37(2001, pp. 371378.

[19] D.D. Woods, Four concepts for resilience and the implications for the future of resilience engineering, Reliability Engineering \& System Safety, 141(2015, pp. 59.

[20] A. Zolli, A.M. Healy, Resilience: Why Things Bounce Back, Simon \& Schuster, City of New York, NY., 2013.

[21] P. Meier, Digital humanitarians: how big data is changing the face of humanitarian response, CRC Press, Boca Raton, FL, USA, 2015.

[22] D. McLoughlin, A Framework for Integrated Emergency Management, Public Administration Review, 45(Special) 1985, pp. 165-172.

[23] A.K. Settle, Financing Disaster Mitigation, Preparedness, Response, and Recovery, Public Administration Review, 45(Special) 1985, pp. 101-106.

[24] K.I. Shoaf, S.J. Rottman, The Role of Public Health in Disaster Preparedness, Mitigation, Response, and Recovery, Prehospital and Disaster Medicine, 15(04) 2000, pp. 18-20.

[25] M. Sakurai, J. Kokuryo, Design of a Resilient Information System for Disaster Response, in: 35th International Conference on Information Systems, Auckland, Newzealand, 2014.

[26] S. Carpenter, B. Walker, M.J. Anderies, N. Abel, From Metaphor to Measurement: Resilience of What to What?, Ecosystems, 4(8) 2001, pp. 765-781.

[27] G.B. Davis, M.H. Olson, Management information systems : conceptual foundations, structure, and development, 2nd ed., McGraw-Hill, New York, 1985.

[28] W.N. Adger, T.P. Hughes, C. Folke, S.R. Carpenter, J. Rockström, Social-ecological resilience to coastal disasters, Science, 309(5737) 2005, pp. 1036-1039.

[29] L.K. Comfort, Self-Organization in Complex Systems, Journal of Public Administration Research and Theory: JPART, 4(3) 1994, pp. 393-410.

[30] S.A. Kauffman, The Origins of Order: SelfOrganization and Selection in Evolution, Oxford University Press, U.S.A., 1993.

[31] D. Mendonça, Decision support for improvisation in response to extreme events: Learning from the response to the 2001 World Trade Center attack, Decision Support Systems, 43(3) 2007, pp. 952-967.

[32] D. Thapa, M.K. Sein, Information Ecology as a Holistic Lens to Understand ICTD Initiatives: A Case Study of OLPC Deployment In Nepal, in: International Conference on Information \& Communication Technologies and Development Michigan, USA, 2016.

[33] M. Warschauer, M. Ames, CAN ONE LAPTOP PER CHILD SAVE THE WORLD'S POOR?, Journal of International Affairs, 64(1) 2010, pp. 33-51. 